\title{
On the Professional Literacy and Innovation Ability of the Library Librarians in Colleges and Universities
}

\author{
Jing ZHANG \\ Library, Nanjing University of Finance and Economics, Nanjing City, China
}

Keywords: University Librarians, Professional literacy, Innovation ability, Cultivation.

\begin{abstract}
At present, there is no consensus on what kind of professional literacy that university librarians should have, which results in the lack of professional spirit and belief of university librarians, furthermore the lack of professional core competence and professional skills. To this end, this paper constructs a professional literacy system for university librarians, which includes moral cultivation, communication skills, professional qualifications and innovation skills.
\end{abstract}

\section{论高校图书馆馆员的职业素养和创新能力}

\author{
张静
}

南京财经大学图书馆, 江苏南京 210023

关健词：高校图书馆馆员；职业素养；创新能力；培育

摘要: 现阶段高校图书馆员应该具备怎样的职业素养尚未取得共识。这将导致高校图书馆馆 员缺乏职业精神和职业信念, 进而导致高校图书馆馆员职业核心能力与职业技能追求与培养 的缺失。为此, 论文构建一套高校图书馆馆员职业素养体系, 该体系由品德修养、沟通能力、 专业资质和创新能力构成。

\section{1. 引言}

在传统的认识里, 高校图书馆馆员就是简单的办理借还书手续、整理图书架等, 与简单 的体力劳动者并无太大不同, 实现的社会价值较低, 认为这个职业人人都可以胜任。随着时 代的飞速发展, 在当下文献资源网络化、信息化的大环境背景下, 随着软硬件的不断升级换 代, 各学科的知识也同样以飞快的速度随之不断更新, 高校图书馆馆员必须调整知识结构, 提高综合素质, 跟上时代变化的节奏。而实现这种自我完善的途径只有一个, 那就是要不断 学习, 与时俱进, 在学习过程中不断成长。面对当前的客观现实, 顺应整个社会文化大环境 和高校图书馆软硬件的变化, 高校图书馆应跳出高校教辅机构的框框, 高校图书馆馆员也应跳 出简单体力劳动者的、被动的服务者的框框, 成为主动的、知识和文化的引领者, 担负起文 献资源信息专家和知识导航员的责任, 努力做到专业的、资深的馆员不是随便就可以被替代, 也不是一朝一夕就可以达到的。那么在此前提之下首先要明确自己的职业定位, 对自己的职 业内涵有清晰的认识, 有明确的职业发展方向, 从而不断提高自己的职业竞争力, 向着专业 化领域发展, 和医生、律师等职业一样有其明确的职业定位, 具备专业性和不可替代性。

但现阶段对高校图书馆员职业素养并没有明确的职业定义和要求, 这种状态会使我们不 清楚我们应该做什么和不应该做什么, 不明确我们的方向和目标在哪里。这种对自己职业精 神与职业信念的缺失最终会导致我们对职业核心能力与职业技能追求与培养的缺失。因此, 明确高校图书馆馆员的职业素养和实现方式是当务之急。 


\section{2. 高校图书馆馆员应具备的职业素养}

\section{1 职业道德}

美国著名作家罗曼・文森特・皮尔说过 “态度决定一切”，冊庸置疑，尊重和爱护读者 应是高校图书馆馆员自始至终应该秉持的态度，是图书馆一切工作的立足点和出发点。而职 业道德应是在具体工作当中得到有效贯彻的行为准则和规范, 具体可从以下这四个方面得到 体现。

\subsection{1 品德修养}

“学艺要先学做人”，这句话可以说是亘古不变、放之四海而皆准的。对于高校图书馆 员来说, 这句话更有着不一样的意义。因为高校图书馆员主要面对的是刚从初等教育阶段进 入到高等教育阶段的年轻学生, 他们求知欲强, 模仿能力强, 心理也不成熟, 正处在由不成 熟走向逐渐成熟的重要阶段。而图书馆在本科生的心目中一直都是一个集美与智慧于一体的 一个很神圣的机构, 那么图书馆员的品德修养在一言一行中都得到体现, 势必对学生产生潜 移默化的、润物细无声的影响。老师是在课堂上解惑授业, 而课堂之外接触较多的就是图书 馆, 高校图书馆馆员的品德修养会对学生的个人素质塑造方面有着非常立体的影响, 产生的 作用可以说是立竿见影而且深远的。

\subsection{2 职业使命感}

职业使命感即自己应该肩负的责任。对高校图书馆员来说，他们应该肩负的责任就是利 用自己的专业知识服务于高校师生读者。使高校图书馆在功能地位上成为文献信息中心、文 化活动中心和自主学习中心。

\subsection{3 职业价值观}

职业价值观即要认可和接受自己的职业，认识到自己所从事职业的价值所在，并且具有 坚定的职业信念和强烈的职业自豪感。

\section{2 沟通能力}

沟通是建立馆员、读者之间相互信任的基础，良好的沟通可以使服务更加顺畅，拉近馆 员与读者的距离, 增进情感, 取得认知, 让工作有效的完成, 使读者满意而归。因此高校图 书馆馆员应具备基本的沟通能力, 需要注意以下四个方面。

\subsection{1 读者第一位}

首先要树立读者立场，始终将读者的要求放在第一位：沟通是信息传递的过程，在这个 过程中馆员应该要有很强的责任心和耐心, 仔细倾听、配合解决。反之, 对读者缺乏耐心、 不能清楚、详细的向读者介绍、说明, 就会容易与读者产生矛盾, 使工作陷入被动局面。

2.2.2 良好的精神面貌

一方面, 人的行为举止对自身的心理状态能够产生很大的影响, 面带微笑的同时自然心 理就放松下来, 在面对学生的时候会更有耐心, 自然工作成效会大不一样。另一方面, 别人 对你的态度可以说是你对别人的态度的一面镜子。作为高校图书馆的工作人员, 学生尊称为 老师。那么言谈举止更要大方、得体, 有长者和为人师表的风范, 学生在面对这样的你的时 候自然会变得放松、容易沟通, 反之, 就会比较尖锐、钻牛角尖, 问题发生时也就不好说服 教育和管理。

\subsection{3 掌握读者心理}

在问题发生前就觉察到, 给读者以明确的引导, 可以及时的终止矛盾的发生,使沟通更有 效、更顺畅, 有效的避免不必要的冲突发生, 将无谓的摩擦降到最低限度, 从而营造出文明、 和谐和温馨的的图书馆学习氛围。

\subsection{4 善于总结经验}

要善于总结经验, 正确的保留坚持, 错误的改善摒弃, 使沟通能力一步一步得到提升。 


\section{3 专业资质}

所谓专业资质,是指必须要掌握的、本专业领域内的核心技能。对于高校图书馆馆员来说， 核心技能主要是指从大量的文献信息中搜集提炼出符合读者需要的文献信息资源,并用精炼 的文字表达出来的能力。具备过硬的专业技能是为读者提供优质服务的重要保证, 主要涉及 以下四个方面知识。

\subsection{1 图情专业知识}

图书情报学是指图书馆业务学科和情报信息学科结合的一门学科。作为高校图书馆的馆 员, 具备图书情报学专业方面的知识是必须的, 是开展图书馆工作的前提和基本条件。

\subsection{2 其他专业知识}

要达到为读者提供全方位、宽领域、深层次的信息服务的目标，那么在掌握图情专业方 面知识的同时, 还要兼备某学科领域的专业背景知识。这样与相应领域的读者沟通起来才能 更顺畅、更深入, 没有阻碍, 不会被晦涩难懂的专业知识难倒或受到限制, 使工作水准难以 达到一定的高度和深度。

\subsection{3 信息挖掘知识}

具备对数量庞大、形式多样的信息源善于发现、挖掘的能力。科学研究获取资料的方式 可分为两种,一是研究者参观访问研究对象;二是通过分析文献材料。通过前一种方式所获取的 是一些直感性材料,一般称为第一手资料;通过后一种方式所获得的是间接性的材料,一般称为 第二手资料。在很多情况下读者需要的信息往往不是从各处搜集来的未经加工过的比较原始 的第一手资料, 而是经过有目标的、有方向性的归纳整理、满足特定读者特定需要的经过二 次加工后的资料。这样省去了读者从搜集到整理, 归纳等一系列的加工环节, 拿到手的是从 原始资料到经过加工处理的满足需求的信息, 而高校图书馆员的价值也就从中得到体现。

2.3.4 计算机及网络应用知识

在网络资源日益增长的今天，读者对电子资源的获取和利用呈现快速增长，这可以说是 不可逆转的趋势, 只有迎头赶上, 提高计算机及网络应用能力, 才能跟上时代的脚步。

\section{4 创新能力}

高校读者的特点可以归纳成 “三高” : 高学历, 高素质, 高要求。因此, 他们与公共图 书馆的社会读者比起来, 更注重图书馆服务的文明性、规范性、技巧性和成效性。为了能跟 上甚至是超过他们的脚步, 高校图书馆员的创新能力显得尤为重要, 固步自封只会使差距越 来越大。尤其是计算机技术、网络技术迅猛发展的大环境下，传统的服务方式已经远远不能 适应形式的变化, 唯有将创新理念渗透到图书馆工作的方方面面, 才能满足读者不断变化的 需求。而创新必须由高校图书馆馆员通过具体实践来落实, 因此, 培养具有创新能力的馆员 显得至关重要。

\subsection{1 树立创新理念}

要有敏锐的观察力, 紧跟时代发展。既要关注行业外的大环境的发展变化, 也要关注行 业内的最新动态, 做到及时更新观念, 及时调整工作方式, 做到与读者的需求更好的对接, 提供更有效的服务。

\subsection{2 创新服务内容}

随着数字图书馆的发展，一般性的服务已经不能满足需求，要求针对不同读者开展个性 化、特色化的信息推送服务:(1) 科研工作方面: 不仅仅停留在常规的学科服务、定题服务等 方面, 在电子资源方面可进行特色数据库研发工作, 建立符合本校办学特色和满足本校科研 需要的特色数据库。(2) 宣传推广工作方面: 在当下 “酒香也怕巷子深” 的时代, 必须做好 宣传推广, 提高实效性和提升工作效果, 及时的将图书馆的最新动态和成果推广出去, 使馆 员的劳动成果得到检验和产生成效。（3)咨询服务工作方面：可基于网络平台，由以往仅仅 局限于校内人力和物力资源的咨询服务推广到校外, 构建与其他学校合作咨询平台, 实现功 能更强大的资源共享前提下的信息咨询和推送服务。（4）专门的学习、科研区域：针对不同 
读者需求或科研性质, 设立专门的场所, 如研究小间、教师沙龙、古籍特藏区等, 形成更具 专业性和规模性的服务分区，以便能更好的提供所需的特定服务。

\section{4 .3 创新服务方法}

现在的在校大学生都是 90 后, 是伴随着网络信息技术成长起来的一代, 比较适应和容易 接受更快捷方便的学习方式。例如: (1) 电子在线座位预约系统: 从根本上改善了学生排长 龙的现象, 为文明自习提供了很好的硬件条件。(2) 自助服务: 有自助复印和打印、自助借 还等自助服务, 简单的自助操作增加了馆藏文献流通量同时也给同学们带来了 “自给自足, 丰 衣足食” 的乐趣。(3) 移动图书馆: 基本的查询书刊借阅状态、续借、挂失等业务都可以在 手机上完成 (4) 微博、微信、博客: 高校图书馆服务对象主要是教师和年轻一代的学生, 他 们接受新事物的能力较强, 可以结合这个特点, 利用微博、微信、博客, 开展相关服务, 为 读者增加利用图书馆的信息渠道。（5）图书导读：在精读、读好书的层面上, 采用定期以展 板的形式推出新书推荐和精品书推荐, 并放置在醒目位置, 为师生爱读书、读好书提供阅读 指南; 也可通过设立读书协会的形式将学生组织在一起, 讨论交流读书心得, 培养良好的阅 读习惯。

\subsection{4 创新服务形式}

针对当下师生的特质, 可采用更活泼、互动性更强的服务形式: (1)阅读推广活动: 以学 生喜闻乐见的形式进行阅读推广活动, 如举办文化节、读书节等, 并设置形式多样的主题活 动, 使学生可以参与其中, 在受到文化熏陶的同时, 也能够个人能力方面得到锻炼, 也能够 产生较大的辐射效应, 影响面较广。(2) 开展竞赛: 以竞赛的形式指导学生写微书评、开展 信息检索素养大赛, 激发其读书热情和培养其文化素养以及提高其网络信息资源的检索能力 (3)用户教育: 在图书馆网页上增加新生入学教育模块, 由面对面教学的形式改为网上答题 形式, 既避免了师生的舟车劳顿, 也节约了教学成本。（4）建立图书阅览区: 在学校学生出 入较密集区域, 设立图书角或阅览室, 方便学生阅读, 为学生读书尽可能的提供方便, 尤其 是在天气不好的时候, 更凸显其方便的特性。（5）设立意见簿：小小的意见簿冲破了传统的 管理与被管理的概念, 转化为服务与被服务的关系, 使服务理念向前迈进了一大步。师生可 以将不适宜当面沟通的意见写到意见簿上, 避免塩㸱的同时又及时的反映了问题, 有利于矛 盾和问题的解决。

\section{3. 结束语}

正如郭沫若所言：“没有一流的图书馆，就没有一流的大学”。高校图书馆馆员的职业 素养直接影响到高校图书馆的服务质量和水平, 从而最终影响到整个学校的办学水准。因此, 在新的信息环境下, 需要馆员以读者需求为根本, 以日新月异的网络信息环境为契机, 以不 断提升自身的职业素养和创新能力为准绳, 有效落实图书馆管理制度和行之有效的工作方式 方法，成为专业扎实、勇于创新的新一代高校图书馆馆员,推进高校图书馆全面发展。

\section{References}

[1] Long Meiying, Zou Yong, The Discussion of the Professional Ethics of the librarians in Harmonious Society, Library. 1 (2008) 76-77.

[2] Xiong Xiaoying, On the Continuous Growth of Librarians, Library and Information Service. S2 (2012) 54-56.

[3] Jin Zhu, On the Librarian's Occupation Spirit and Core Ability, Library Journal. 9 (2005) 6-7.

[4] Fan Li, The Quality and Cultivation of Subject Librarians in University Libraries, Guizhou Library Publication. 2 (2016) 5-7. 
[5] Wen Rou, On the Strategy to Improve the Service Ability of Librarians in the "Internet +" Times, Journal of Library Science. 1 (2017) 46-48.

[6] Tao Qian, Liu Yongjie, Content Analysis on Professional Competence Standards of American Special Librarians, Library and Information Service. 24 (2016) 20-25.

[6] Zhang YanYan, Yu Bo, Guo Lei, Wen Liangming, Research on the Service Innovation of University Library in an Era of Fragmented Reading, Library Development. 4 (2017) 44-50. 